\title{
Estructura y transformación del comercio minorista en el norte de la región metropolitana de Buenos Aires
}

Lorena Vecslir ${ }^{1}$ | Florencia Elisa Sciutto ${ }^{2}$

Recibido: 06-12-2020 | en su versión final: 23-02-2021

\begin{abstract}
Resumen
Los estudios que se enfocaron en las centralidades metropolitanas de Buenos Aires dieron cuenta de una jerarquía de centros en relación a la cantidad y complejidad de equipamientos públicos y servicios financieros, contrapuestos a la presencia de shopping centers. Respecto de la actividad comercial, estos aportes han sido de gran utilidad, pero requieren de lecturas complementarias que permitan explicar la compleja estructura territorial del comercio minorista, más allá de la dicotomía centro histórico vs shopping center. Con este objetivo, en base a datos de Google Maps y otras fuentes complementarias, se elaboraron mapas de diversidad e intensidad comercial que nos permitieron avanzar en la interpretación de los patrones espaciales de esta actividad, con foco en el eje norte de la región. Las cartografías generadas muestran una estructuración lineal de los locales relevados a lo largo de antiguas rutas y avenidas supramunicipales, y una concentración nodal en torno a las estaciones ferroviarias. Al mismo tiempo, se identifican algunas tendencias recientes de transformación o revitalización comercial, incluyendo nuevos productos "a cielo abierto" como shoppings de cercanía y polos gastronómicos. La incorporación al mercado de estas tipologías coexiste con los esfuerzos municipales de renovación de sus centros tradicionales, sobre todo a partir de intervenciones de mejora del espacio público.
\end{abstract}

Palabras clave: Centralidad; comercio y consumo; estructura territorial; renovación urbana

Citación

Vecslir, L. y Sciutto, F.E. (2021). Estructura y transformación del comercio minorista en el norte de la región metropolitana de Buenos Aires, ACE: Architecture, City and Environment, 16(46), 9889. DOI: http://dx.doi.org/10.5821/ace.16.46.9889

\section{Retail Structure and Transformation in the North of the Metropolitan Region of Buenos Aires}

Abstract

\begin{abstract}
Previous studies focused on the metropolitan centralities of Buenos Aires showed a center hierarchy in relation to the amount and complexity of public facilities and financial services, in contrast to the presence of shopping centers. These contributions have been very useful regarding commercial activity, but they require additional analysis to explain the complex territorial structure of retail, going beyond the dichotomy of historical center vs shopping center. For this purpose, based on Google Maps data and other complementary sources, we drew up commercial diversity and intensity maps that allowed us to advance in the interpretation of this activity spatial patterns, with a focus on the northern axis of the region. These cartographies show a linear structuring of the gathered stores along old supramunicipal routes and avenues, and nodal concentrations around railway stations. At the same time, we identify some recent trends in retail transformation or revitalization, including new "open-air" products such as proximity shoppings and gastronomic poles. The real state incorporation of these typologies coexists with the municipal efforts in the renewal of their traditional centers, mainly through urban interventions of public space improvement.
\end{abstract}

Keywords: Centrality; retail and consumption; territorial structure; urban renewal

${ }^{1}$ Dra. Arquitecta, Investigadora Independiente, Consejo Nacional de Investigaciones Científicas y Técnicas de Argentina (CONICET), Instituto de Geografía, Facultad de Filosofía y Letras, Universidad de Buenos Aires (UBA) (ORCiD: 0000-0003-0130-7808), 2 Arquitecta, Investigadora, Instituto de Geografía, Facultad de Filosofía y Letras, Universidad de Buenos Aires (UBA) (ORCiD: 0000-0003-0387-3846). Correo de contacto: lorena.vecslir@conicet.gov.ar 


\section{Introducción}

Los patrones de consumo y uso de tiempo libre en la Región Metropolitana de Buenos Aires (RMBA) ${ }^{1}$ han ido cambiando al ritmo de las transformaciones territoriales de las últimas tres décadas; entre aquellas más evidentes: las nuevas opciones residenciales, el desarrollo de las infraestructuras de comunicación, la reestructuración de los servicios, los espacios de trabajo y emergencia de nuevos "centros de comando". ${ }^{2}$

Estas dinámicas han sido acuciantes en el eje norte de la RMBA, especialmente en su frente costero -municipios de Vicente López, San Isidro, San Fernando y Tigre- a partir de emprendimientos inmobiliarios de urbanizaciones cerradas y condominios con amenities, nuevos complejos de oficinas, shoppings y multicines, articulados por las mejoras y ampliaciones de la autopista Panamericana (Acceso Norte) y sus tres ramales a Tigre, Pilar y Escobar. Mientras que las áreas centrales fueron escenario de operaciones públicas y desarrollos inmobiliarios en sus zonas históricas, portuarias y costeras (Colella, 2013).

En este corredor, los estudios urbanos han destacado la propagación del shopping center como "artefacto de la globalización", paralelamente a la pérdida de vitalidad de los centros o subcentros tradicionales, estructurados en proximidad a las estaciones ferroviarias (Vidal-Koppmann, 2010). Una mirada que puede extenderse al conjunto de la RMBA y bajo la cual podemos enmarcar desde los trabajos seminales de jerarquización de centros realizados por la Comisión Nacional Área Metropolitana de Buenos Aires (CONAMBA) en 1995, hasta las más recientes iniciativas de renovación de las centralidades tradicionales bajo el modelo de Centros Comerciales a Cielo Abierto (CCCA), fundamentadas por sus impulsores como respuesta a los embates del shopping center y el "conflicto" del comercio ambulante (Vecslir y Rodríguez, 2018).

Sin embargo, consideramos que no es posible reducir el rol del comercio minorista y los espacios del ocio y el consumo a estos dos formatos (shopping vs calle comercial) ni emplazamientos (centro vs periferia). En una región metropolitana con una compleja estructura socio territorial, que mantiene un alto dinamismo del comercio de calle tanto en los centros tradicionales, como en las principales rutas y avenidas, las inmediaciones de los intercambiadores de transporte, los nuevos distritos gastronómicos, de la moda y el diseño, existen aspectos que permanecen insuficientemente explicados, siendo necesario profundizar en su abordaje tanto desde los estudios urbanos locales como desde las políticas públicas en sus distintos niveles decisorios.

Desde esta perspectiva, con el foco puesto en el uso comercial minorista, el presente trabajo se orienta a la construcción de cartografías alternativas a los esquemas tradicionales de jerarquización de centros según lógicas christallerianas y criterios de proximidad centro-periferia. A partir del procesamiento y cruce de datos provenientes de Google Maps, se generan mapas de diversidad e intensidad comercial que dan cuenta de los patrones de localización de esta actividad en la RMBA. Al mismo tiempo, con base a un relevamiento de notas periodísticas y trabajo de campo, complementado por verificaciones en Google Street View, se identifican algunas tendencias recientes de transformación tipológica en el eje norte, más allá del formato clásico de shopping center o big box.

\footnotetext{
1 La RMBA abarca la Ciudad Autónoma de Buenos Aires (CABA), los 24 municipios circundantes que forman la primera y segunda corona de la aglomeración, también denominados Conurbano Bonaerense (CB), y los 16 municipios de la tercera corona. En conjunto, comprende un área de 19.680 km² y una población que hacia 2020 se aproxima a los 15 millones habitantes.

2 Zonas de concentración de equipamientos, funciones y actividades vinculadas al comando de la economía regional, nacional y del capitalismo global (Ciccolella, 1999: pág. 17).
}

ACE, 16 (46) CC BY-ND 3.0 ES | UPC Barcelona, España | Estructura y transformación del comercio minorista en el norte de la región metropolitana de Buenos Aires. DOI: $\underline{\text { http://dx.doi.org/10.5821/ace.16.46.9889 }}$ 
Se parte de la base que la lectura interpretativa de estas configuraciones de la actividad comercial puede servir para identificar dinámicas más amplias de reestructuración metropolitana, incluidas aquellas de escala barrial, y especificidades de cada contexto que han tendido a ser soslayadas por los estudios urbanos enfocados en los artefactos y efectos territoriales de la globalización. En la misma dirección, se considera que este tipo de estudios puede aportar hacia la diversificación de las políticas urbanas, hoy principalmente canalizadas hacia operaciones de CCCA.

Con base a estas premisas, en el primer apartado del artículo se mencionan los antecedentes más representativos del estudio de la centralidad comercial para el caso de la RMBA. En el segundo se realiza una lectura de la estructura territorial actual del comercio minorista a partir de los datos de Google Maps. El tercero hace foco en el corredor norte, con la detección de patrones de localización recurrentes. El cuarto describe algunas tipologías recientes, tales como los shoppings de cercanía, nuevos polos gastronómicos y centros tradicionales renovados. Por último, se reflexiona sobre el carácter de las transformaciones y la potencialidad de estos análisis como insumo para la toma de decisiones sobre la estructura comercial metropolitana.

\section{2. "Desconcentración concentrada" y centralidad comercial en la RMBA}

Existe consenso en el campo de los estudios urbanos acerca de la importancia del "comercio de calle", ${ }^{3}$ tanto como sector económico con alta capacidad de generación de empleo, como por su aporte al dinamismo y la vitalidad urbana, su rol vertebrador del tejido y de cohesión social (Gehl y Savarre, 2013). Se ha resaltado como cualidad, la resiliencia de tiendas y distritos comerciales frente a las condiciones cambiantes que desafían el equilibrio del sistema minorista, conservando su viabilidad económica y capacidad de respuesta a las necesidades de diferentes grupos de consumidores, incluidos los más desfavorecidos (Barata-Salgueiro, 2011). Paralelamente a la extensión fragmentaria y de baja densidad de las áreas metropolitanas, el comercio de proximidad ha sido considerado como una actividad clave en la configuración de la ciudad compacta y, por tanto, un valor a preservar, revitalizar y propagar desde las políticas públicas (López de Lucio, 2006).

Por otra parte, diversos estudios han analizado la densidad comercial como variable fundamental en la detección de centros y subcentros metropolitanos (por ejemplo, Truffello e Hidalgo, 2015; Ruiz Lineros y Marmolejo Duarte, 2008), utilizando los datos de empleo en comercio minorista, así como la densidad de compradores, derivada de encuestas de movilidad cotidiana. Los resultados de estos trabajos coinciden en señalar la evolución de las respectivas áreas metropolitanas de estudio hacia estructuras cada vez más policéntricas, partiendo de la idea que policentrismo y dispersión son procesos muchas veces simultáneos (García-López y Muñiz Olivera, 2007), capaces de dar lugar, utilizando la figura de Dematteis (1998), a una "desconcentración concentrada" de empleos, comercios y servicios.

En las metrópolis latinoamericanas, de acuerdo con De Mattos, este proceso paralelo de expansión urbana y descentralización de servicios colaboró en "la revitalización y modernización de muchos de sus antiguos corredores comerciales, con fuerte impacto en la reorganización urbana”. Así, a las nuevas concentraciones territoriales desarrolladas a partir de shopping centers y centros de negocios, se suman estas centralidades "que resultaron del fortalecimiento, diversificación y ampliación de actividades comerciales tradicionales para el consumo cotidiano local, muchas veces configuradas linealmente a lo largo de ciertas arterias o corredores de antigua tradición comercial" (De Mattos, 2010: pág. 97).

\footnotetext{
${ }^{3}$ Nos referimos a "comercio de calle" en contraposición al comercio alojado en grandes superficies, malls o shopping centers. Estas dos tipologías no necesariamente coinciden con una localización determinada (central o periférica), resultando frecuente la existencia de corredores comerciales en áreas suburbanas, así como de shoppings implantados dentro del tejido consolidado de la ciudad compacta.
}

ACE, 16 (46) CC BY-ND 3.0 ES | UPC Barcelona, España | Estructura y transformación del comercio minorista en el norte de la región metropolitana de Buenos Aires. DOI: http://dx.doi.org/10.5821/ace.16.46.9889 
El caso de la RMBA comparte estas tendencias y patrones de crecimiento urbano disperso, difusión de grandes superficies comerciales y centros corporativos, y fortalecimiento de estructuras comerciales lineales, a la vez que presenta algunas singularidades que la diferencian de otras metrópolis latinoamericanas. La llegada tardía del shopping center, ${ }^{4}$ su origen urbano con una concentración destacada en la CABA (Capron, 1996), ${ }^{5}$ sumado a la fortaleza del comercio tradicional en las áreas próximas a las estaciones ferroviarias, las grandes avenidas y arterias metropolitanas, resultan los principales rasgos distintivos.

En este marco, frente a la difusión tardía pero bastante potente del shopping center y las nuevas cadenas de hipermercados que se dio durante los años '90, las investigaciones focalizaron su mirada en los efectos urbanos de estos procesos producto de la globalización (Capron, 1996; Guttman, 1997; Ciccolella, 2000). Bajo esta óptica, la centralidad tradicional fue revalorizada en contraposición a la "hipermercadización" y el acelerado crecimiento del shopping center, haciendo hincapié en el rol de este último como destino de las grandes inversiones privadas, factor de concentración comercial y competencia con el comercio minorista.

Simultáneamente a estos estudios, un análisis realizado por la CONAMBA (1995) se propuso jerarquizar 115 localidades de la región metropolitana de acuerdo a la cantidad y complejidad de actividades de equipamiento social e, institucional, servicio financiero, comunicación y transporte presentes en cada centro. Dicho trabajo fue actualizado una década más tarde y permitió la comparación entre los "centros tradicionales" y las "nuevas centralidades", que fueron relacionadas directamente con la presencia de shopping centers (Abba, 2005). Quedaron definidas así para los años 1994 y 2004 tres jerarquías de centralidades con similar dotación de funciones, cuyos alcances se circunscriben, respectivamente, a localidades, municipios y región metropolitana (Figura 1).

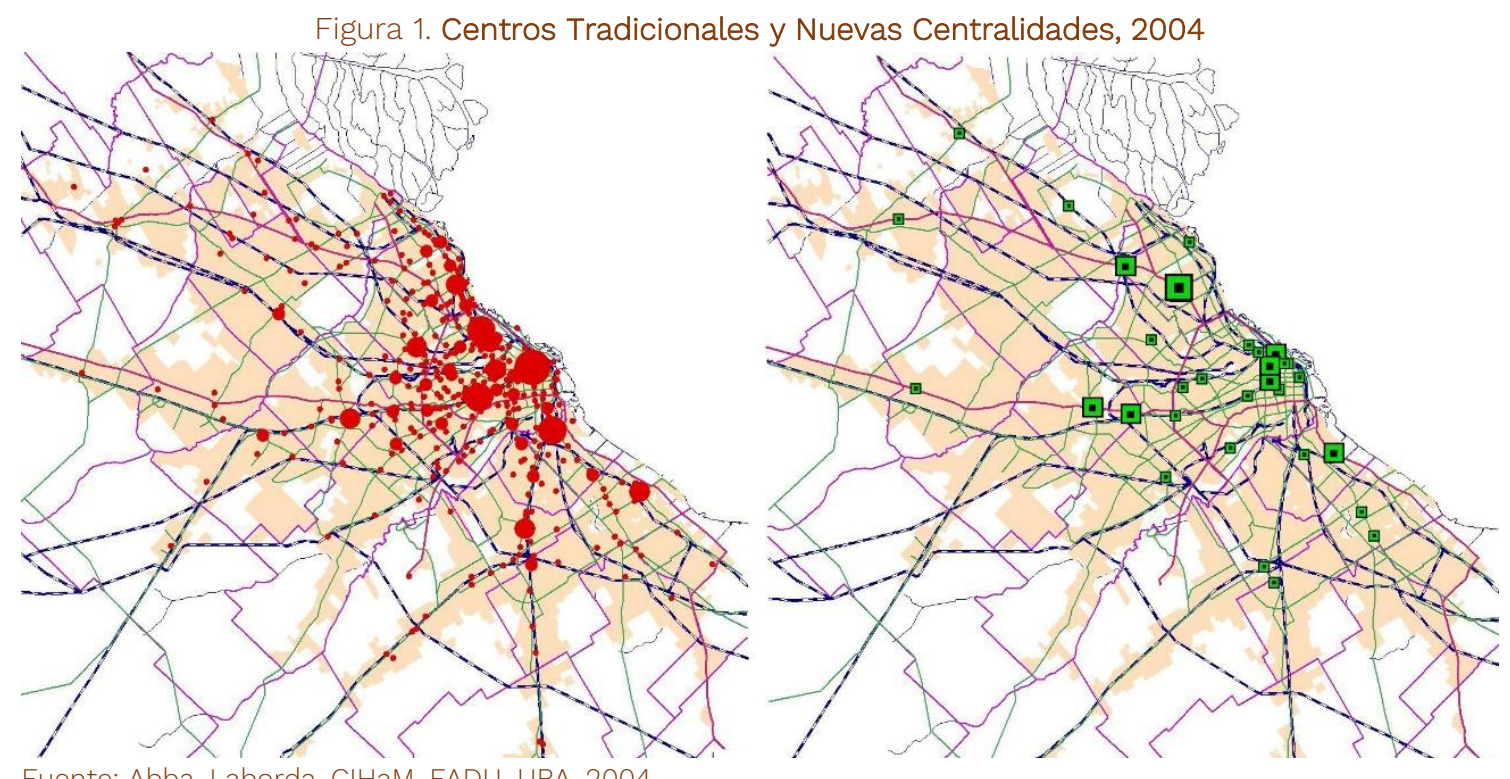

Fuente: Abba, Laborda, CIHaM, FADU, UBA, 2004.

\begin{abstract}
${ }^{4}$ El primer centro comercial en América Latina fue el Iguatemi, inaugurado en San Pablo en 1966. Recién veinte años más tarde entró en funcionamiento el primer mall de Buenos Aires: el Shopping Sur (1986), cuya actividad cesó en 1997. La siguiente apertura significativa fue, en 1988, la del Unicenter, el primer centro comercial regional de Argentina con una superficie de $155.000 \mathrm{~m}^{2}$ (más $86.000 \mathrm{~m}^{2}$ de estacionamiento cubierto).

${ }^{5}$ Mientras que los primeros centros comerciales de San Pablo, Guadalajara, Bogotá o Santiago de Chile fueron concebidos -siguiendo el modelo norteamericano de shopping regional- como nodos o enclaves periféricos; en Buenos Aires la difusión espacial se hizo principalmente desde el centro hacia los barrios de la capital y la periferia metropolitana.
\end{abstract}

ACE, 16 (46) CC BY-ND 3.0 ES | UPC Barcelona, España | Estructura y transformación del comercio minorista en el norte de la región metropolitana de Buenos Aires. DOI: http://dx.doi.org/10.5821/ace.16.46.9889 


\section{ACE Architecture, City and Environment}

E-ISSN 1886-4805

De manera complementaria, dentro del mismo estudio, el equipo coordinado por Horacio Bozzano realizó un relevamiento de los usos del suelo e identificó una serie corredores que alternaban usos comerciales, de servicios, depósitos y en menor medida industriales, atravesando uno o varios partidos de la región metropolitana. Estos corredores se estructuraban a lo largo de ciertos ejes viales, en su mayoría radiales, cuya función original de conectividad intrametropolitana perdió peso frente a la propia del corredor, es decir, transporte público y concentración de actividades. A partir de la lectura de fotografías aéreas (escala 1:20.000, año 1992), se elaboró un mapa -dibujado a mano- de los usos reales del suelo que discriminaba una serie de categorías híbridas con indicación del uso dominante (comercial, residencial, industrial). Tal como puede observarse en un fragmento de dicho mapa, correspondiente al sector norte de la RMBA (Figura 2), la categoría "tejido comercial dominante con residencia y/u oficinas en propiedad horizontal" (representada en color rojo) dio cuenta de la existencia de este tipo de configuración lineal de la centralidad, no contemplada por los esquemas de ordenación jerárquica de centro y subcentros, ni por los instrumentos de planificación vigentes.

Figura 2. Fragmento del mapa Usos del Suelo 1992

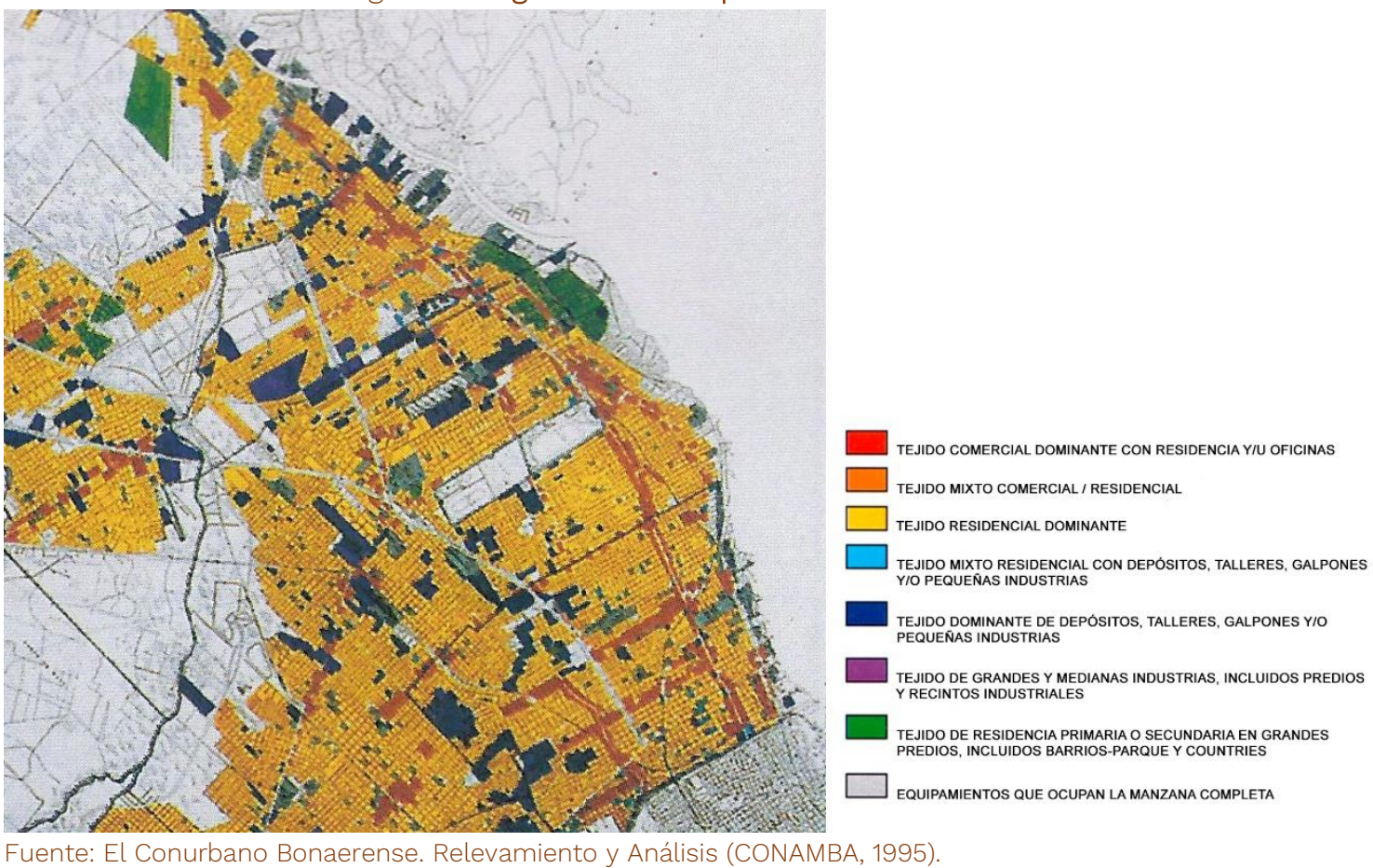

A partir de los años 2000, la crítica al shopping center y la privatización del espacio público se vio complementada por otro tipo de análisis de la centralidad metropolitana que puso el foco en el patrón de localización de los edificios de oficinas premium. ${ }^{6}$ Este layer de información territorial sirvió para identificar los "centros de comando" de la economía global que, pese a mantener una alta presencia en el área central tradicional de la CABA, mostraban una tendencia creciente de localización en la zona norte de la RMBA, con una concentración significativa en torno de dos corredores paralelos a la costa del Río de la Plata: Acceso Norte y Av. del Libertador (Vecslir y Ciccolella, 2011).

\footnotetext{
${ }^{6}$ Dentro del negocio inmobiliario, el segmento de oficinas premium o clase A+ se caracteriza por su localización en parques empresariales o polos corporativos, una dimensión de planta tipo mayor a $600 \mathrm{~m} 2$, sistemas de seguridad y acondicionamiento "inteligentes", certificación o sello energético, diseño y acabados de calidad, entre otros requisitos. En general se trata de emprendimientos de nueva construcción, aunque existen edificios reciclados posicionados en el mercado premium.
}

ACE, 16 (46) CC BY-ND 3.0 ES | UPC Barcelona, España | Estructura y transformación del comercio minorista en el norte de la región metropolitana de Buenos Aires. DOI: http://dx.doi.org/10.5821/ace.16.46.9889 
Más recientemente, el relevamiento de algunas localidades del eje sur dio cuenta de un proceso de revitalización comercial y verticalización residencial de antiguas centralidades que habían entrado en una fase de estancamiento y deterioro a mediados de la década de 1970 (Ciccolella, Vecslir y Baer, 2015). Mientras que, en ciertos municipios del norte de la RMBA, en cambio, el comercio de calle había quedado relegado frente a los nuevos enclaves del ocio y el consumo, los cuales fueron estudiados en relación a su contexto inmediato de implantación a fin de entender las relaciones funcionales, espaciales y sociales que este tipo de artefactos eran capaces de desencadenar (Vecslir, 2018).

Pese a todos estos trabajos, consideramos que las transformaciones del shopping bonaerense, la revitalización de los centros tradicionales y la consolidación de corredores comerciales y de servicio supramuncipales, continúan siendo procesos escasamente estudiados, con dimensiones analíticas vacantes más allá de la discusión sobre la ciudad global y los cambios sociales en las prácticas de consumo.

\section{Del dato al mapa: nuevas cartografías del comercio minorista}

En este marco y a fin de generar un mayor conocimiento de los patrones de localización y características tipológicas del comercio de calle en la RMBA, realizamos un mapeo y análisis de los sistemas de oferta comercial urbana en los municipios de esta región, en base a los datos provistos por Google Maps y Google Street View. Se trató de reproducir el tipo de relevamientos efectuado por la CONAMBA, ahora con los recursos on-line disponibles como fuente primaria de información.

En otros contextos, algunos estudios recientes dan cuenta de las posibilidades que ofrecen plataformas como Open Street Maps (Limonta y Paris, 2017) o el cruce entre censos de actividades, datos catastrales y de redes sociales (Sevtsuk, 2010; Carpio-Pinedo, 2014) para realizar lecturas más detalladas, e incluso evaluar la accesibilidad y el comportamiento social en los entornos comerciales. A nivel local, existen ejemplos como el "Mapa de oportunidades comerciales", construido en 2017 desde Ministerio de Modernización en base a tecnologías de big data, el cual permite conocer los riesgos y oportunidades de abrir un negocio en la CABA de acuerdo a información como el número de tiendas del mismo rubro, cantidad de personas que transitan la zona y precios de alquileres de locales. $^{7}$

En nuestro trabajo, se realizó un relevamiento de locales comerciales a partir de los datos provistos por la plataforma Google Maps. El relevamiento general llevado a cabo en una primera instancia fue luego sistematizado y reorganizado según categorías más abarcativas, desarrolladas a continuación. El objetivo metodológico fue lograr un escaneo continuo y exhaustivo de las acumulaciones comerciales en los partidos de la RMBA, que a su vez permitiera poner en evidencia centralidades comerciales o cúmulos de pequeña escala más allá de su jerarquía o su jurisdicción de pertenencia. ${ }^{8}$

Los datos obtenidos, que incluyen aproximadamente 80 tipos de comercio, fueron luego clasificados en función de tres grandes categorías (Figura 3):

- Espacios de consumo: Aquellos destinados a la adquisición de productos. Incluyen locales de indumentaria (ropa, calzado, deportes, lencería, accesorios, joyerías), abastecimiento (almacenes, kioscos, farmacias, perfumerías, supermercados express, fiambrerías, casas de

\footnotetext{
${ }^{7}$ La plataforma trabaja con "datos abiertos" provistos por la Agencia Gubernamental de Control, la dirección de Estadísticas y de Planeamiento Urbano, la Administración Gubernamental de Ingresos Públicos, BA Data y la plataforma Properati de análisis del mercado inmobiliario. https://moc.buenosaires.gob.ar/

${ }^{8}$ Cabe aclarar que, para optimizar la visualización, la aplicación restringe los campos pertenecientes a la búsqueda a 60 resultados. Por tanto, se efectuó una repetición de las búsquedas por categoría en los "sitios próximos a la vista actual" para maximizar la cantidad de resultados obtenidos.
}

ACE, 16 (46) CC BY-ND 3.0 ES | UPC Barcelona, España | Estructura y transformación del comercio minorista en el 6 norte de la región metropolitana de Buenos Aires. DOI: http://dx.doi.org/10.5821/ace.16.46.9889 
comida, panaderías, rotiserías, deliverys, vinotecas, librería, ferreterías, casas de iluminación, mercerías), hogar y tecnología (electrodomésticos, venta de celulares, casas de iluminación, casas de decoración, bazares), periféricos (viveros, mueblerías, autopartes, concesionarios, outlets).

- Servicios: locales donde se adquieren prestaciones. Abarcan servicios financieros, aseguradoras y bienes raíces (bancos, cajeros automáticos, aseguradoras, mutuales, inmobiliarias), servicios personales (gimnasios, centros de estética, spa, peluquerías, manicuras, depilación), servicios de reparación (zapatero, cerrajería, plomería, modista, tintorería, audio-video, electrodomésticos), servicios profesionales (abogados, contadores, ópticas, veterinarias).

- Espacios "consumibles". donde se consumen productos y servicios con fines de entretenimiento o socialización. Por ejemplo, locales gastronómicos (bares, cervecerías, restaurants, heladerías), discotecas y salones de fiesta, actividades culturales (centros culturales, teatros, cines, galerías de arte, museos). Incluso ciertos espacios públicos podrían incluirse en esta categoría, "especialmente aquellos que han sido remodelados o diseñados, ya no sólo para cumplir las funciones de un equipamiento urbano, sino para actuar como símbolo y escaparate de un modelo de ciudad" (Benach, 2000, p.196).

Figura 3. Estructura comercial en la RMBA

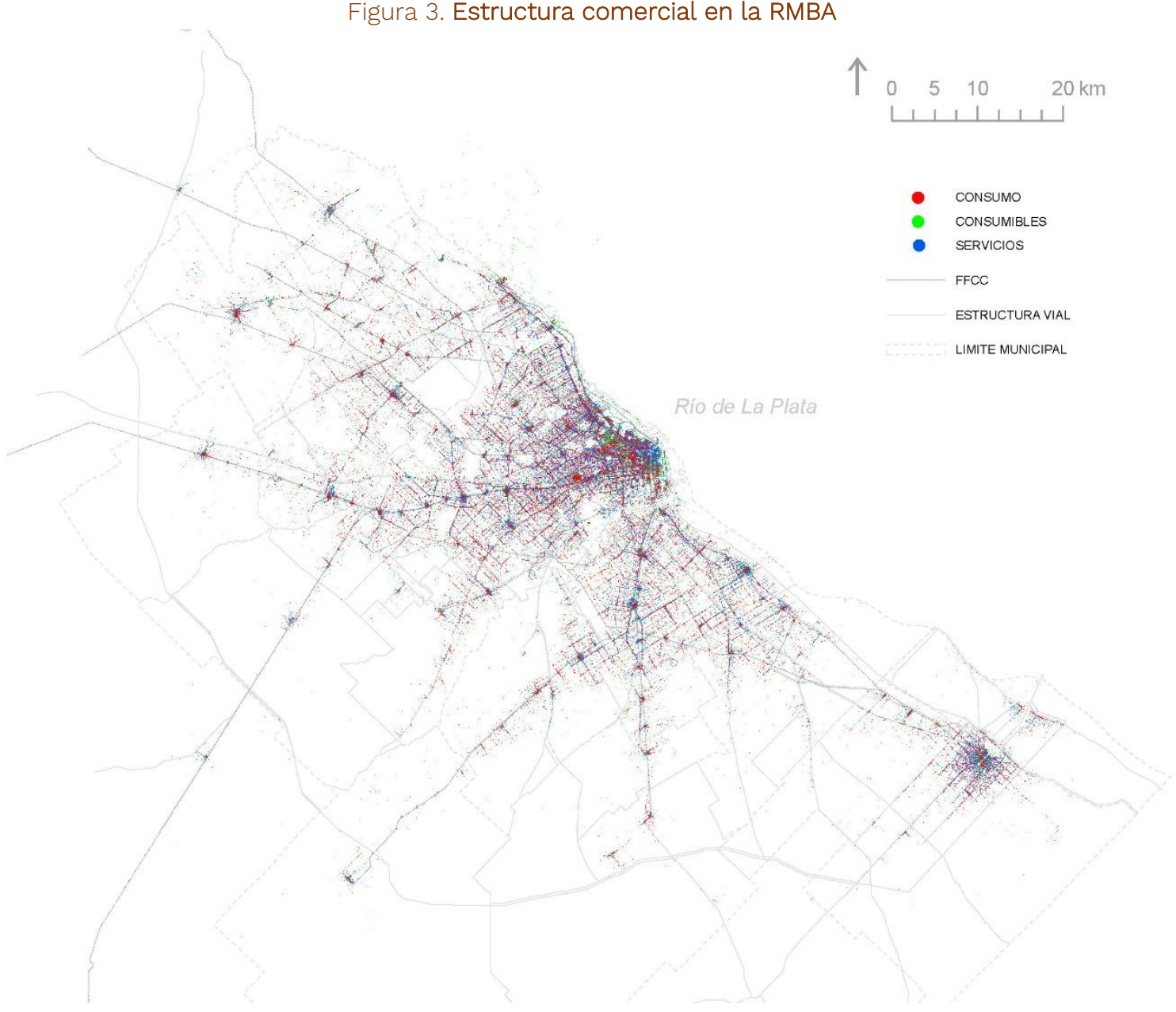

Fuente: Elaboración propia a partir de datos Google Maps (2018).

ACE, 16 (46) CC BY-ND 3.0 ES | UPC Barcelona, España | Estructura y transformación del comercio minorista en el norte de la región metropolitana de Buenos Aires. DOI: http://dx.doi.org/10.5821/ace.16.46.9889 
La cartografía obtenida da cuenta de una concentración nodal del comercio en proximidad a las estaciones ferroviarias, donde llegan a superarse los 50 locales por hectárea. Cabe aclarar que la RMBA cuenta una extensa red ferroviaria, constituida por siete líneas de trenes suburbanos que datan de finales del SXIX. Esta red nace con el fin de transportar la producción agrícola hasta el puerto bonaerense, al mismo tiempo que cumple un rol fundamental en la configuración del crecimiento metropolitano. El esquema radial y monocéntrico que caracteriza la estructura territorial tiene origen en ese periodo, con la consolidación de los centros urbanos secundarios en torno de las principales estaciones donde actualmente se aglomeran las funciones comerciales, administrativas y de servicio.

De acuerdo con este modelo de urbanización, la mayor densidad comercial resulta coincidente con dichos centros $y$, en líneas generales, disminuye desde CABA hacia las sucesivas coronas metropolitanas. A pesar de la fuerte caída de las ventas minoristas en la RMBA en el contexto de crisis sanitaria, ${ }^{9}$ el comercio de calle constituye aún un sector muy dinámico. Esto se manifiesta en la alta tasa de ocupación de locales de las principales avenidas, intercambiadores de transporte y distritos de la moda y el diseño de la CABA, así como en los sectores próximos a las estaciones ferroviarias de las localidades cabeceras de los partidos de la primera y segunda coronas metropolitanas (Avellaneda, Quilmes, Lanús, Lomas de Zamora, Monte Grande, San Justo, Morón San Martín, San Miguel, Vicente López, San Isidro, Tigre, etc.).

Paralelamente, tal como hemos anunciado, destaca la concentración lineal de locales en torno de vías arteriales radiales y transversales que atraviesan uno o más partidos de la región metropolitana (rutas provinciales 202, 36, 4, rutas nacionales 197, 7, 3, entre otras). Se trata de antiguos ejes de movilidad que han perdido su rol de tráfico de paso, y cuya intensidad comercial -a manera de electrocardiograma- aumenta en proximidad a las zonas más densamente pobladas, mutando hacia un tipo de comercio suburbano especializado (muebles, repuestos, concesionarios de automóviles, ferreterías, corralones de construcción, viveros, etc.) al alejarse de las mismas.

Por último, pero no menos significativo, existe una subestructura de locales destinados a servicios y comercio cotidiano de escala barrial, que se infiltra en las mallas residenciales e industriales preexistentes.

El predominio de una estructura lineal del comercio que caracteriza la cartografía anterior, obtenida en base a los datos provistos por Google Maps, contrasta con el patrón nodal de los "centros tradicionales", jerarquizados en tres niveles (principal, secundario, barrial) de acuerdo a la presencia de actividad bancaria, considerando la concentración de actividad financiera minorista como representativa de la existencia de nodos de bienes y servicios centrales (Figura 4)..$^{10}$

En el mismo mapa se superpusieron los 45 shoppings centers mayores a $10.000 \mathrm{~m}^{2}$ existentes en la RMBA. "1 Éstos primero se consolidaron en la CABA, contiguos al centro principal y luego se extendieron hacia otros sectores de la ciudad, muchas veces producto de operaciones de reciclaje de edificios con valor patrimonial (Patio Bulrich, Galerías Pacífico, El Solar, Abasto). Unicenter (1988) y Soleil Factory (1987) fueron los primeros emprendimientos de shopping suburbano, mas cercanos al modelo original de cuño norteamericano, que se implantaron en la primera corona del eje norte pero buscando extender su radio de influencia a las urbanizaciones cerradas emergentes mas allá de la

\footnotetext{
${ }^{9}$ Según un informe elaborado por la Confederación Argentina de la Mediana Empresa (CAME) en julio de 2020, las ventas minoristas en el área metropolitana de Buenos Aires cayeron un 36,3\% respecto a igual mes de 2019 , mientras continuó ganando mercado el comercio on-line (https://www.redcame.org.ar/novedades/9818/ventasminoristas-pymes-resultados-del-mes-de-julio-2020)

10 La fuente de este layer de información es el trabajo realizado por Artemio Abba en 2004 en el marco de los Lineamientos Estratégicos para la Región Metropolitana de Buenos Aires (Abba, 2005).

${ }^{11}$ Los centros comerciales menores a $10.000 \mathrm{~m}^{2}$ coinciden con un formato de reciente desarrollo en la RMBA: los shoppings de cercanía. Éstos se analizan en el último apartado del trabajo como nuevos productos comerciales.
}

ACE, 16 (46) CC BY-ND 3.0 ES | UPC Barcelona, España | Estructura y transformación del comercio minorista en el 
misma. En la actualidad, del total de shoppings relevados, 17 se sitúan en la CABA y 28 en la región metropolitana. La mitad de estos últimos se ubican en la zona norte, próximos a los ramales del Acceso Norte hacia Tigre, Pilar y Escobar. Destaca su implantación aislada, próxima a enlaces o accesos viarios, en general en áreas donde anteriormente no existían funciones comerciales, actuando como "locomotora" o atractor de la actividad empresarial (oficinas, edificios corporativos), de grandes equipamientos privados (universidad, clubes deportivos, centros de salud), e incluso de nuevas formas de alojamiento temporal (hotel corporativo, suites, home \& office).

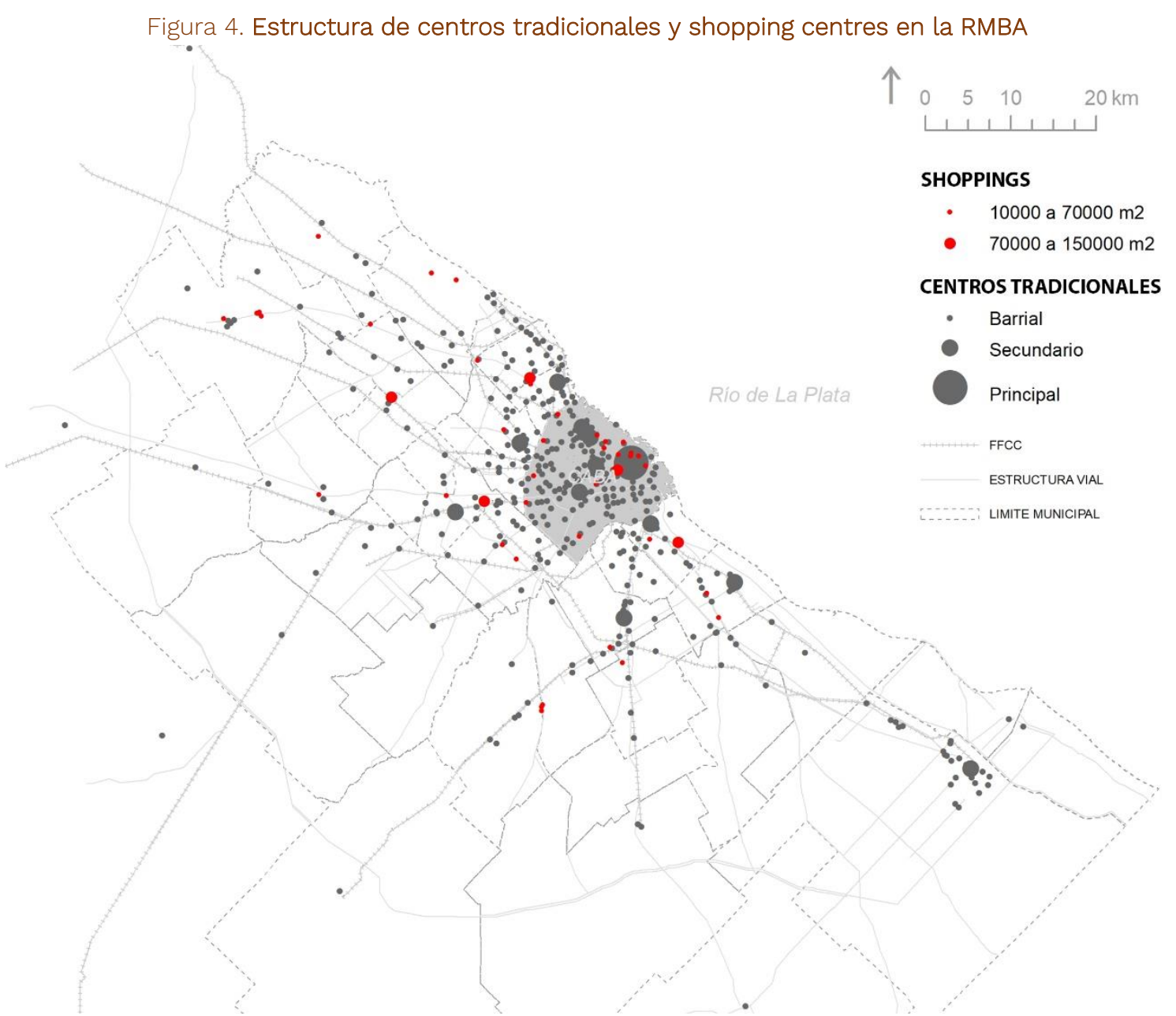

Fuente: Elaboración propia a partir de Lineamientos Estratégicos para la Región Metropolitana de Buenos Aires (Dirección Provincial de Ordenamiento Urbano, 2005) y datos de la Cámara Argentina de Shopping Centers.

\section{Patrones de localización del comercio en el corredor norte}

A fin de avanzar en la caracterización particular de la estructura comercial de los distintos sectores territoriales en los que normalmente se divide la RMBA, ${ }^{12}$ se realizó un acercamiento al corredor norte, más específicamente a los municipios correspondientes a la primera corona de la franja costera:

\footnotetext{
12 Para el análisis de la RMBA suelen diferenciarse tres coronas o "cordones" según la distancia de los municipios respecto a CABA, y tres zonas según su orientación (norte, oeste y sur).
}

ACE, 16 (46) CC BY-ND 3.0 ES | UPC Barcelona, España | Estructura y transformación del comercio minorista en el norte de la región metropolitana de Buenos Aires. DOI: http://dx.doi.org/10.5821/ace.16.46.9889 
Vicente López, San Isidro, San Fernando y oeste de Tigre, estructurados por el ferrocarril Mitre, la autopista Acceso Norte, la Av. Maipú-Santa Fe-Centenario y la Av. Del Libertador (Figura 5).

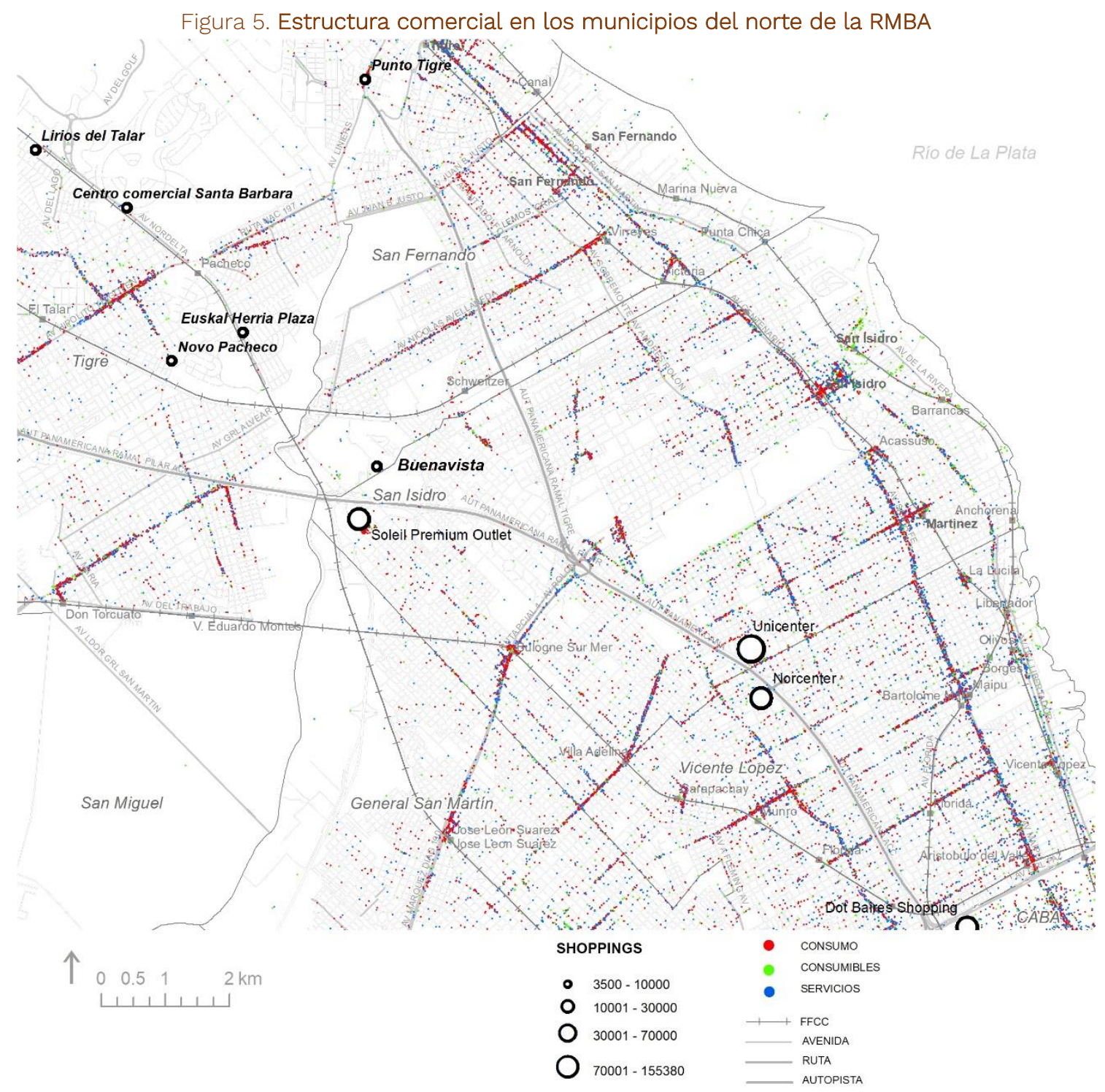

Fuente: Elaboración en base a relevamiento propio de shoppings centers (2019) y datos de Google Maps (2018).

Este corredor se caracteriza por concentrar el mayor número de urbanizaciones cerradas de la RMBA, así como los complejos empresariales y parques industriales más modernos. Como contracara, abarca simultáneamente amplios sectores residenciales para clase media y baja, incluyendo villas y asentamientos. En el recorte específico seleccionado, destaca la presencia de grandes vacíos urbanos (Jockey Club, Hipódromo, Aeropuerto de San Fernando, Campo de Mayo), en alternancia con barrios cerrados, áreas más densamente pobladas y grandes proyectos inmobiliarios. Estos últimos, cercanos a la ribera de Vicente López y Olivos, se han desarrollado bajo la tipología de torres, destinadas a vivienda para clase alta y media alta, así como para albergar sedes de empresas multinacionales, especialmente a lo largo de la Av. del Libertador.

ACE, 16 (46) CC BY-ND 3.0 ES | UPC Barcelona, España | Estructura y transformación del comercio minorista en el norte de la región metropolitana de Buenos Aires. DOI: http://dx.doi.org/10.5821/ace.16.46.9889 
La costa del Río de la Plata y el Delta reúnen espacios de ocio y turismo (tren de la Costa, Parque de la Costa, Puerto de Frutos, marinas y clubes náuticos) y, por tanto, aglutinan gran parte de los espacios "consumibles" relevados. Las mayores concentraciones de espacios de "consumo" y "servicios" han estado tradicionalmente asociadas a las principales avenidas paralelas a la costa y los entornos de las estaciones ferroviarias. Estas áreas, que habían perdido cierto dinamismo en la década de 1990 con la aparición de las grandes superficies comerciales (shopping centers, hipermercados, multicines), ${ }^{13}$ han recobrado protagonismo en las últimas décadas, reforzadas por las intervenciones municipales de CCCA (Colella, 2013).

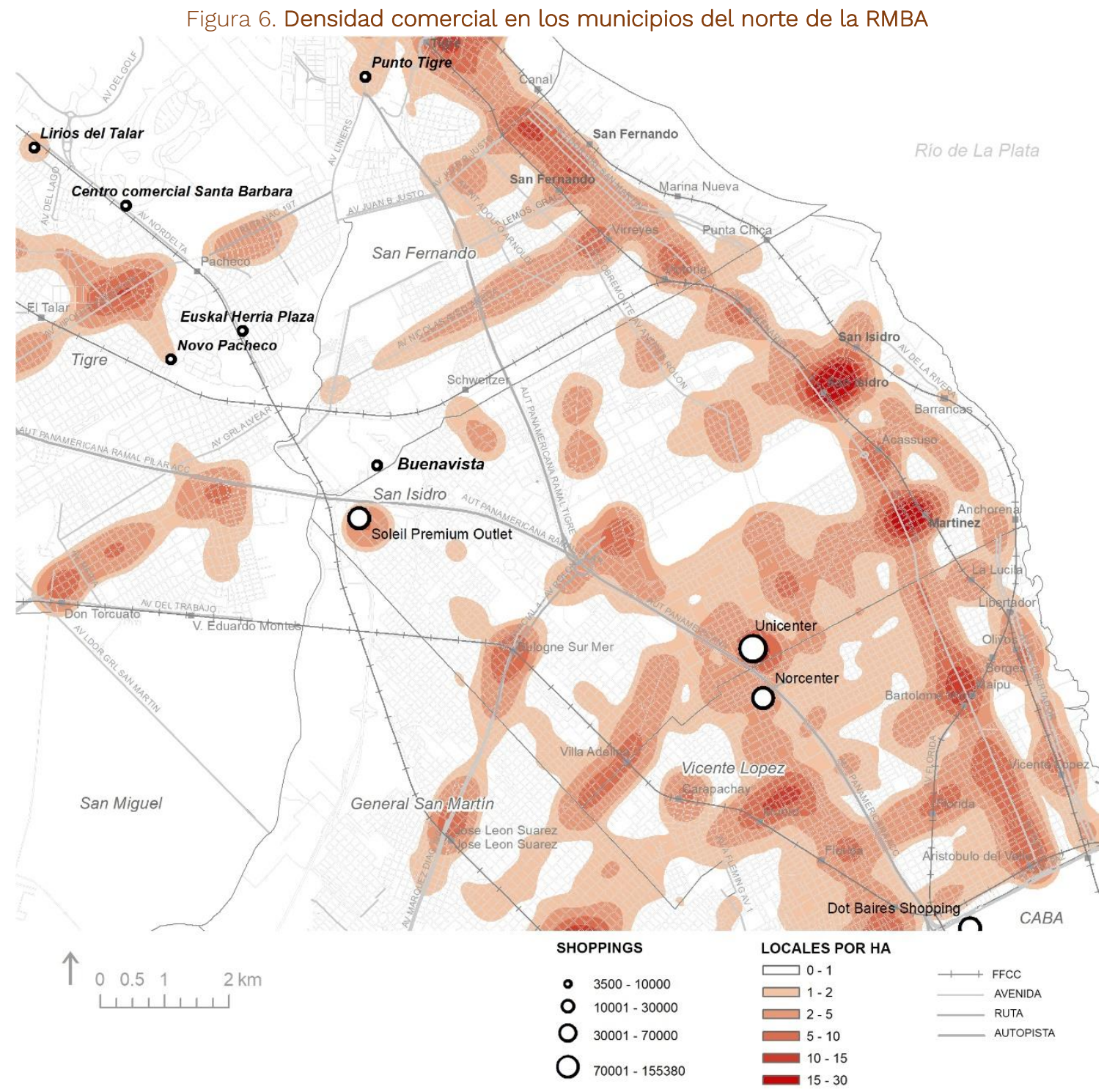

Fuente: Elaboración en base a relevamiento propio de shoppings centers (2019) y datos de Google Maps (2018).

\footnotetext{
${ }^{13}$ Los shoppings más antiguos de la región, Unicenter y Soleil (1988 y 1987), se encuentran en este sector, en el $\mathrm{km} 17$ y el cruce del Acceso Norte con el Camino del Buen Ayre.
}

ACE, 16 (46) CC BY-ND 3.0 ES | UPC Barcelona, España | Estructura y transformación del comercio minorista en el norte de la región metropolitana de Buenos Aires. DOI: http://dx.doi.org/10.5821/ace.16.46.9889 
Para indagar acerca de la existencia de posibles homogeneidades en la distribución de las densidades comerciales en el territorio analizado y cuantificarlas, se procesó la nube de puntos obtenida de los datos de Google Maps. El análisis se realizó mediante el método de Kernel, reclasificando la escala de valores obtenidos de acuerdo a la distribución de cortes naturales (Jenks).

A partir de las isolíneas obtenidas se calculó la densidad de los puntos utilizando la hectárea como unidad geográfica (Figura 6).

La cartografía obtenida permitió corroborar una mayor densidad comercial y de servicios en proximidad a las estaciones ferroviarias donde se registran entre 15 y 30 locales por hectárea. La magnitud de estas concentraciones llega hasta las 40 ha de superficie, siendo las más importantes: Martínez, San Isidro, San Fernando y Tigre. En torno a la Av. Maipú, y su continuación como Av. Santa $\mathrm{Fe} \mathrm{y} \mathrm{Av}$. Centenario, se genera una aglomeración lineal casi ininterrumpida a lo largo de $15 \mathrm{~km}$. Asimismo, destacan algunos ejes comerciales, transversales a los anteriores, como las rutas 202 y 197, con mayor intensidad de actividad a la altura de las localidades de Don Torcuato, General Pacheco y El Talar (municipio de Tigre); la ruta 4, especialmente en la localidad de Boulogne Sur Mer (San Isidro); y la Av. Nicolás Avellaneda en la localidad de Virreyes (San Fernando).

De esta manera, podemos identificar algunos patrones de localización recurrentes, como se muestran en la Figura 7, incluyendo (de izquierda a derecha):

- $\quad$ los entornos de las estaciones ferroviarias (ej. estación San Isidro)

- $\quad$ los bordes de los ejes viales paralelos a la costa (ej. tramo de la Av. Maipú)

- $\quad$ los bordes de los ejes viales transversales (ej. tramo de la ruta 202)

- $\quad$ Los espacios de las bajadas de la autopista (ej. Acceso Norte, bajada Paraná y Debenedetti)

La infiltración de locales de comercio y servicio en las mallas residenciales existentes termina de completar el repertorio de cúmulos de actividad, en este caso de alcance más barrial, pero no necesariamente circunscriptos a la población del partido en el que se implantan, mostrando junto a los anteriores patrones de localización, dinámicas más complejas de relación intra e intermunicipal.
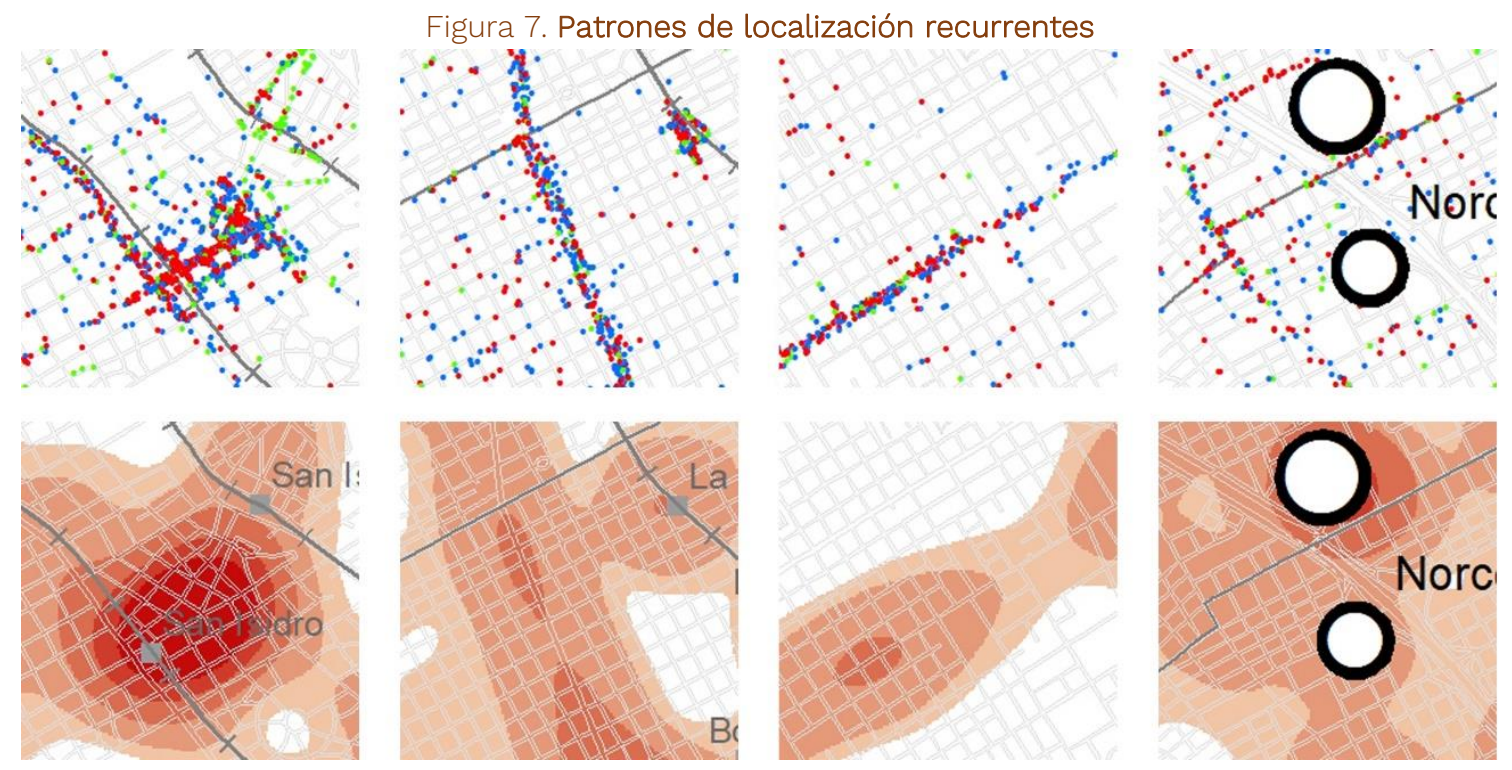

Fuente: Elaboración propia.

ACE, 16 (46) CC BY-ND 3.0 ES | UPC Barcelona, España | Estructura y transformación del comercio minorista en el norte de la región metropolitana de Buenos Aires. DOI: http://dx.doi.org/10.5821/ace.16.46.9889 


\section{Nuevos y renovados productos comerciales}

El aspecto tipológico de las transformaciones del comercio minorista es, a su vez, un campo poco explorado desde los estudios urbanos que, como se ha mencionado, parecen haber quedado anclados a una mirada nostálgica del comercio de calle en la ciudad compacta, contrapuesta al arquetipo del shopping center como "espacio comercial originalmente cerrado, rodeado de estacionamientos, socialmente homogéneo y ubicado en el suburbio" (Salcedo y De Simone, 2013: pág. 126).

Un acercamiento al área de estudio, con base al relevamiento de notas periodísticas y trabajo de campo, permitió matizar esta mirada dicotómica e identificar algunas tendencias recientes de transformación hacia configuraciones más "abiertas" de los formatos, por lo menos si los comparamos con el clásico shopping center de los años 90 al que hace referencia la mayor parte de la literatura disciplinar.

En este sentido, podríamos hablar de una "evolución" de la caja cerrada o big box al formato de paseo de compras -shopping village u open mall-, y de éste al shopping de cercanía o lifestyle center. Las crecientes inauguraciones de estos últimos dan cuenta de la proliferación de un formato de pequeña dimensión (entre 3.500 y $10.000 \mathrm{~m}^{2}$ ) que surge en respuesta a la demanda de productos y servicios cotidianos, proveniente de la población asentada en urbanizaciones cerradas. Desde el 2006 a la actualidad, se construyeron 15 shoppings de cercanía en la RMBA, 11 de ellos ubicados en cuatro municipios de la zona norte: San Fernando, Tigre, Escobar y Pilar. Las figuras 5 y 6 muestran el caso de los centros comerciales Lirios del Talar, Santa Barbara, Euskal Herria, Novo Pacheco y Buenavista, emplazados a lo largo del corredor Bancalari-Benavidez y Av. Nordelta que da acceso a numerosas urbanizaciones cerradas.

Así como en los primeros countries de la RMBA existían las proveedurías y quioscos próximos al club house, el objetivo del shopping de cercanía es aportar -de manera más completa y sofisticadaespacios comerciales y de encuentro para los consumidores de aquellos antiguos emprendimientos y de los nuevos barrios cerrados. ${ }^{14}$ Según referentes del mercado inmobiliario "en vez de pedir que la gente se acerque, son (los centros comerciales) los que se acercan a la gente" para atender la demanda de poblaciones que por su estilo de vida y consumo prefieren no trasladarse a la hora de realizar sus actividades cotidianas. ${ }^{15}$

De esta manera, los desarrollos están compuestos por un programa mixto que incluye, además de los locales comerciales, consultorios externos de distintas especialidades médicas, oficinas y despachos profesionales e incluso, en algunos casos, vivienda. La imagen del centro comercial busca recrear un espacio de pequeña escala, con edificaciones dos o tres plantas de altura, intercaladas por espacios abiertos (plazas, anfiteatros, áreas de juegos para niños) y recorridos peatonales.

En lo que se refiere específicamente a las actividades comerciales se distinguen: aquellas de abastecimiento y servicio cotidiano (supermercado, cajero, farmacia, cafetería, heladería, pet-shop, librería, peluquería, gimnasio); los locales de diseño o con una oferta diferencial (vinoteca, deli, sushi, dietética, uniformes escolares, juguetería); así como franquicias, especialmente de indumentaria, que compensan la menor afluencia de público con el mayor poder adquisitivo de los clientes (Figura 8).

\footnotetext{
${ }^{14}$ Dentro de la categoría de urbanizaciones cerradas, en Argentina, el country se diferencia del barrio cerrado por su origen más antiguo, en general ocupando el terreno de antiguas estancias donde se generan lotes de grandes superficies (de 2500 a $4000 \mathrm{~m}^{2}$ ); por contar con áreas comunes para el encuentro social y la práctica deportiva (golf, polo, tenis); y por su destino predominante como casa de fin de semana. El barrio cerrado se orienta, en cambio, a vivienda permanente, con lotes más pequeños y económicos, y con menores costes de expensas por mantenimiento, ya que casi no existen espacios y equipamientos compartidos.

${ }^{15} \mathrm{https}$ ://www.lanacion.com.ar/economia/los-shoppings-de-proximidad-una-nueva-tendencia-de-consumoque-se-impone-nid1331529
}

ACE, 16 (46) CC BY-ND 3.0 ES | UPC Barcelona, España | Estructura y transformación del comercio minorista en el norte de la región metropolitana de Buenos Aires. DOI: http://dx.doi.org/10.5821/ace.16.46.9889 


\section{ACE Architecture, City and Environment}
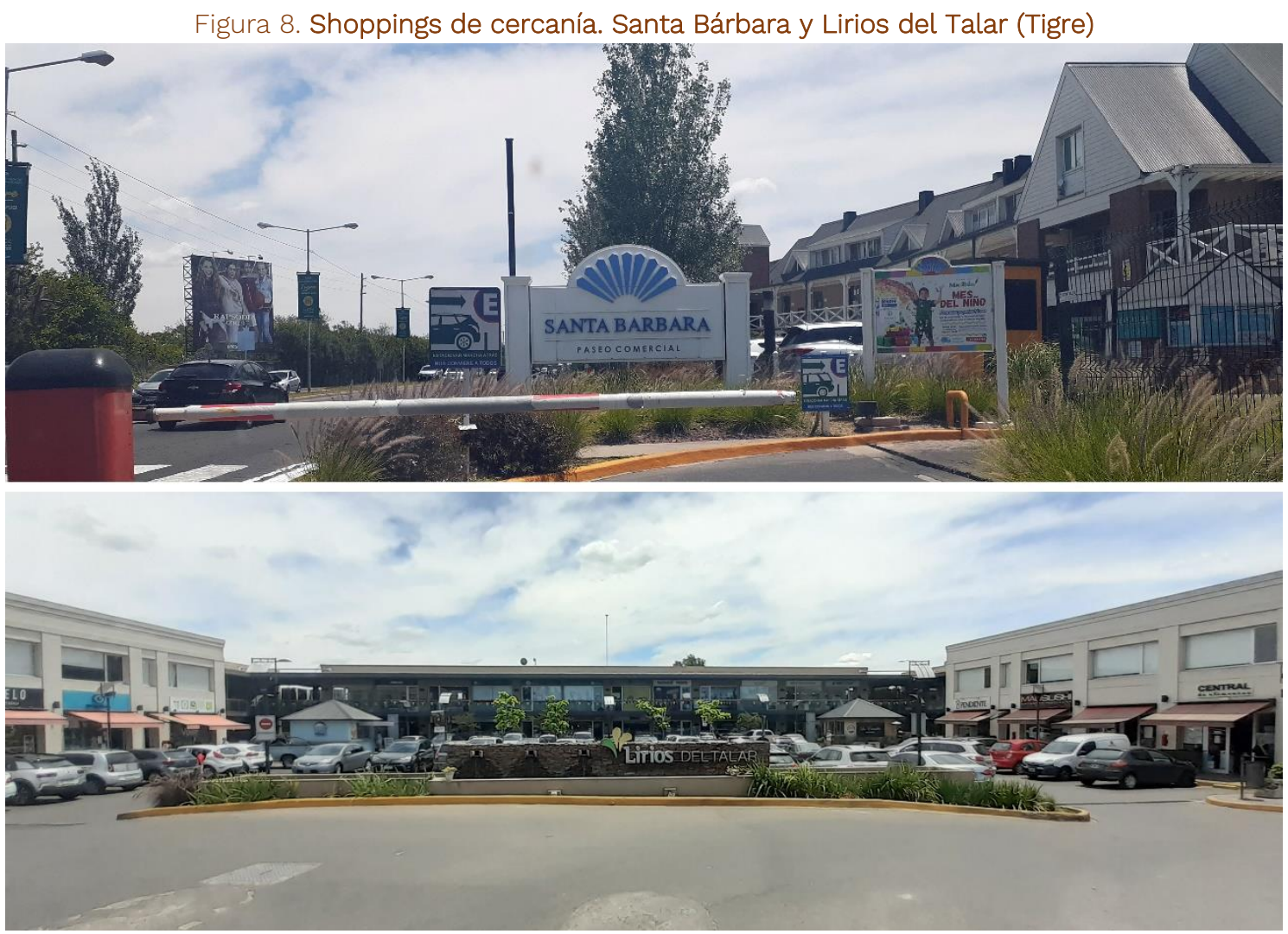

Fuente: Fotografías propias.

Paralelamente al shopping de cercanía, se registra el surgimiento de nuevos polos gastronómicos y de diseño en diversas localidades de la RMBA. En la CABA, las cantinas, bodegones, bares, cafés, restaurantes, pizzerías o parrillas de Palermo Viejo y Palermo Hollywood, Las Cañitas, Av. Caseros, Doho, entre otros, se han ido sumando a los tradicionales polos gastronómicos de Recoleta, Puerto Madero, San Telmo. De manera conjunta, la promoción y puesta en valor de nuevos espacios y mercados, las ferias y concursos de comida, son algunas de las iniciativas del gobierno local orientadas a diversificar las zonas donde vivir distintas experiencias gastronómicas. ${ }^{16}$ Una actividad que ha pasado de actuar como subsidiaria de otros atractores a constituir ella misma un motivo de viaje y/o experiencia turística, con frecuencia capitalizada por las políticas públicas locales como recurso económico (Rodríguez, 2018).

Pero estas transformaciones no se limitan a la CABA. En la zona norte de la RMBA existen casos como la calle Mendoza y el Mercado eco-friendly de Ingeniero Maschwitz (Escobar), el boulevard Saenz Peña y la feria Sabe La Tierra en Tigre, o la Av. Libertador en Punta Chica (San Fernando) que atraen usuarios de los propios partidos y partidos vecinos, pero también, durante el fin de semana, público proveniente de la CABA. En estos enclaves se combina una oferta gastronómica gourmet (hamburguesas de autor, patios cerveceros, cafés de especialidad, locales de delicatessen, heladerías artesanales, restós de comida étnica), con locales de indumentaria de diseñadores independientes, casas de decoración, anticuarios, talleres de artistas plásticos y shows al aire libre. Algunos casos, como el Mercado de Maschwitz o La Aldea en Pilar, han recreado una ambientación estilo vintage mediante el reciclaje de containers, el uso de materiales de demolición, chapas acanaladas, maderas patinadas, empedrados, herrajes y cerramientos antiguos (Figura 9).

${ }^{16}$ https://soloporgusto.com/ba-capital-gastronomica/ 


\section{ACE Architecture, City and Environment}

Figura 9. Polos gastronómicos. Calle Mendoza y Mercado de Maschwitz (Escobar)
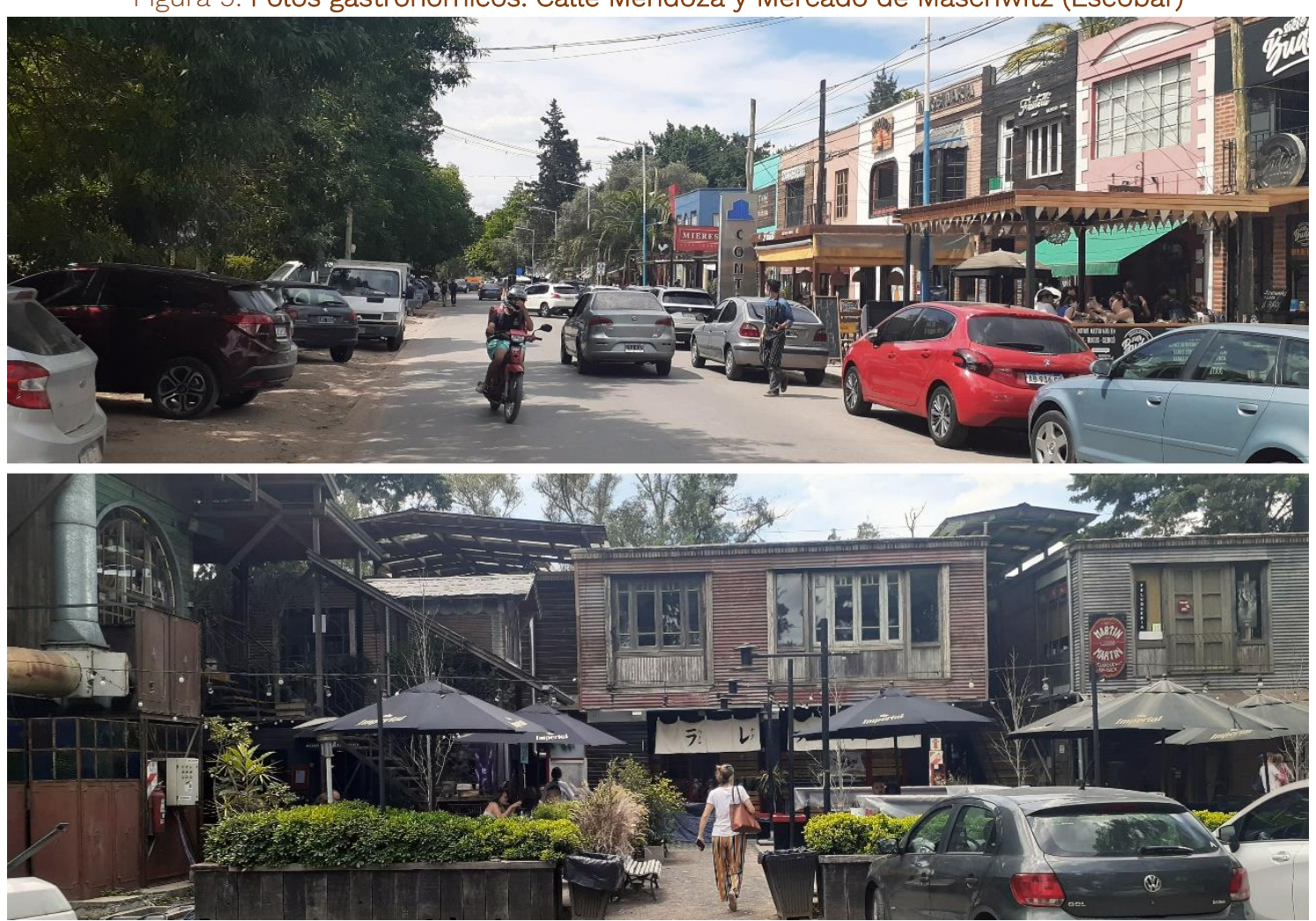

Fuente: Fotografías propias.

Otra tendencia de transformación del comercio minorista que interesa mencionar es aquella impulsada desde las políticas municipales para la recuperación de los centros tradicionales de las principales localidades de la RMBA. Se trata de los acuerdos formulados entre la Confederación Argentina de la Mediana Empresa (CAME) -que canalizó fondos BID a través del Programa PROCOM (Programa de fortalecimiento al comercio minorista)- y diversos municipios de la región para el desarrollo de Centros Comerciales a Cielo Abierto (CCCA).

La versión local del modelo español de $\mathrm{CCCA}^{17}$ ha poblado los subcentros tradicionales de la RMBA de calles renovadas sobre la misma imagen urbana. Con distinto grado de concreción existen 33 iniciativas de CCCA en la RMBA (Vecslir y Rodríguez, 2018) que se traducen en propuestas de urbanización del espacio público (peatonalización, cambios de solado, soterramiento del cableado eléctrico, nueva luminaria, códigos de cartelería) y de animación y promoción comercial (campañas de marketing, eventos culturales).

La mayor parte de los CCCA ejecutados se despliegan sobre uno o dos de los ejes con más dinamismo comercial, próximos a las estaciones ferroviarias, en una extensión que varía de dos a diez cuadras. Los respectivos gobiernos municipales han sido los mayores responsables en la ejecución y el financiamiento de los proyectos, que involucraron la urbanización del espacio público y las acciones de promoción comercial, fases durante las cuales la CAME actuó como un asesor de la Municipalidad,

\footnotetext{
${ }^{17}$ En Argentina, con base en antecedentes españoles (Málaga, Valencia, San Sebastián, Villaviciosa- Asturias, Bilbao, Vitoria y Pamplona, entre otras), el CCCA es definido como un "conjunto de comercios y servicios que comparten una zona geográfica de la ciudad (distrito o eje urbano central, intermedio o periférico), que deciden ofrecer una imagen unitaria de calidad sustentable» (CAME, 2016, p. 4).
} 


\section{ACE Architecture, City and Environment}

las asociaciones de empresarios (cámaras de comercio e industria) y, eventualmente, otras organizaciones públicas y privadas (entes de turismo, colegios profesionales, entidades financieras).

En el sector seleccionado del eje norte, las iniciativas concretadas -aunque sea parcialmenteincluyen los centros tradicionales de San Fernando (calle Constitución) y San Isidro (calle 9 de julio y Belgrano), y los sectores comerciales de Munro (Vicente López) y Don Torcuato (Tigre). Los acuerdos con la CAME de los dos primeros datan de 2011 y los proyectos se extienden a lo largo de 10 cuadras cada uno, habiéndose realizado (entre 2014 y 2017) operaciones de ensanchamiento de veredas, mejora de desagües pluviales y mobiliario urbano. Los recursos para financiar los trabajos provinieron de los propios municipios, con la colaboración de los comerciantes en el caso de San Fernando y derivados de la recaudación del estacionamiento medido, en el de San Isidro.

Este tipo de intervenciones se desarrolla dentro de los límites político-administrativos y, por tanto, no atiende la particularidad que presentan muchos de los ejes comerciales referidos anteriormente, caracterizados por su continuidad funcional a lo largo de antiguas arterias que unen localidades del mismo y de otros partidos de la región metropolitana. En el caso de estudio, el dinamismo económico de las rutas nacionales 202 y 197, o de la ruta provincial 4, contribuye a reforzar las relaciones intermuncipales, en sentido transversal o concéntrico respecto al esquema radial dominante de ejes principales que desembocan en el centro de CABA. Si bien algunos municipios han realizado obras de mejora del espacio peatonal, señalética y mobiliario urbano en los tramos de mayor intensidad comercial, como el caso de Tigre en la Av. Angel T. de Alvear -ruta 202- (Figura 10), la potencialidad de estas centralidades lineales como respuesta a la matriz monocéntrica que tradicionalmente ha guiado el planeamiento metropolitano, no ha sido contemplada desde una mirada integral por los instrumentos de planificación vigentes.

Figura 10. Centro comercial a cielo abierto. Calle Constitución (San Fernando) y ruta 202 (Tigre)
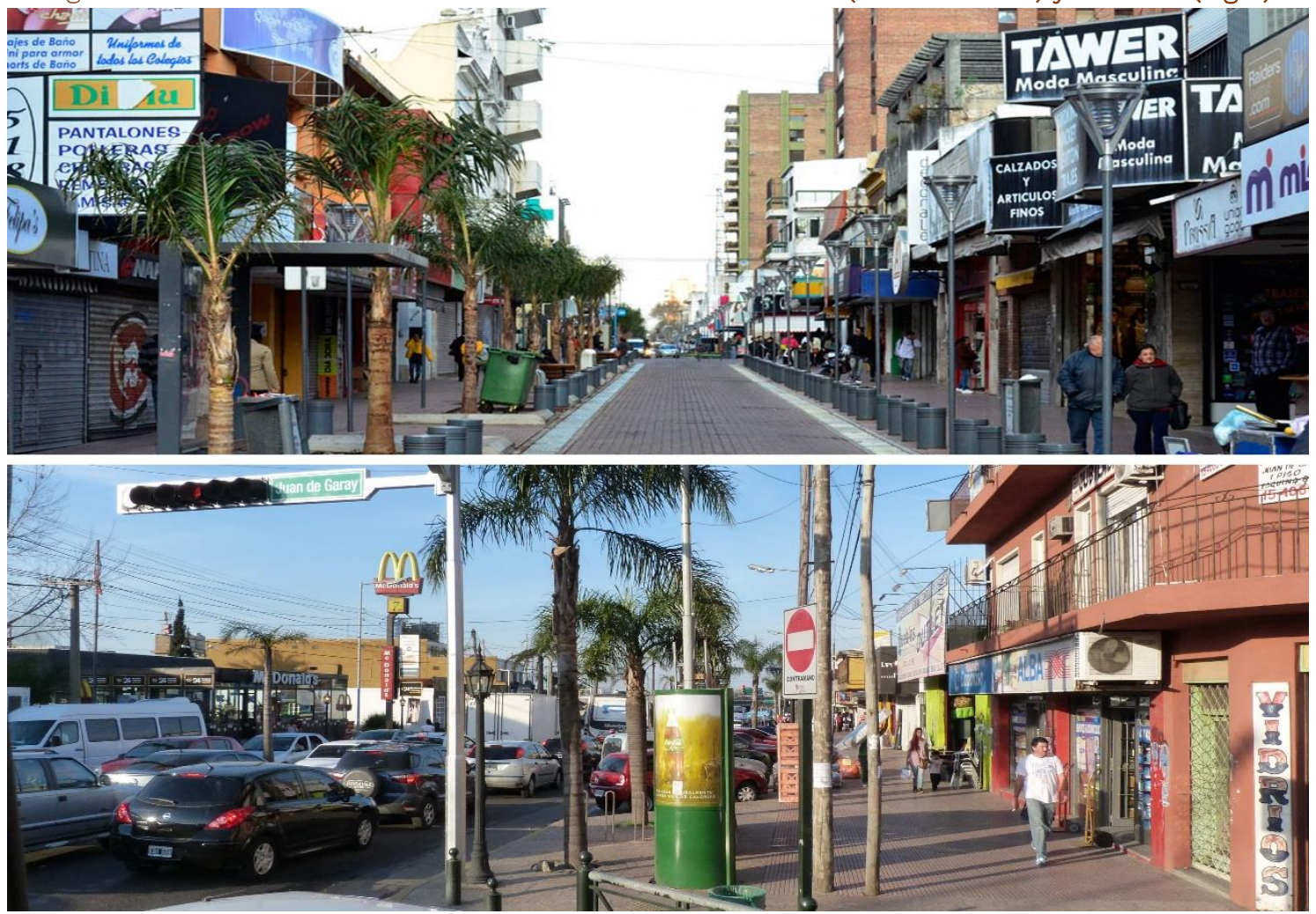

Fuente: https://www.elcomercioonline.com.ar/articulos/50056765-Se-abrio-la-nueva-extension-de-la-calleConstitucion-en-San-Fernando.html (sup.), fotografía propia (inf.)

ACE, 16 (46) CC BY-ND 3.0 ES | UPC Barcelona, España | Estructura y transformación del comercio minorista en el 16 norte de la región metropolitana de Buenos Aires. DOI: http://dx.doi.org/10.5821/ace.16.46.9889 
Las configuraciones del comercio minorista no se agotan en las descritas. En los espacios de bajada y vías colectoras de la autopista, así como en las calles laterales a los shoppings, surgen comercios o servicios complementarios (locales de decoración, restaurantes, gimnasios, agencias de viajes, alquiler de autos y remises, outlets de indumentaria, etc.) a partir del reciclaje de viviendas unifamiliares, antiguos depósitos o en forma de contenedores ex novo. Los entornos de otros grandes artefactos no comerciales como centros médicos, universidades privadas y equipamientos deportivos también aglutinan pequeño comercio con tipologías más o menos innovadoras, sin olvidar las ferias o concentraciones del comercio informal ("saladitas" y "manteros"), ${ }^{18}$ de localización puntual en el corredor de estudio (en proximidad de estaciones ferroviarias, bajadas de autopista e intercambiadores de transporte), pero que adquieren gran relevancia en otros sectores de la RMBA. ${ }^{19}$

\section{Notas de cierre}

El análisis realizado sobre el comercio minorista en la RMBA, con foco en el corredor norte, nos permite reflexionar, en primer lugar, acerca del carácter de las transformaciones, las cuales no siempre implican total renovación. La vitalidad de los corredores comerciales supramunicipales, las operaciones de centros a cielo abierto, así como la emergencia de ciertos distritos gastronómicos contiguos a los centros tradicionales, evidencian la consolidación de patrones históricos de implantación del comercio minorista. Incluso los recientes formatos del shopping de cercanía o los polos gastronómicos de nueva implantación directamente relacionados con las modalidades residenciales de baja densidad, buscan recrear configuraciones más cercanas al comercio de calle que al shopping cerrado, el big box característico de los años '90. A diferencia de otras metrópolis donde la emergencia o completa sustitución de las estructuras existentes por artefactos del ocio y el consumo caracteriza la oferta comercial como parte integrante de las "nuevas centralidades" metropolitanas, el relevamiento y mapeos generados para la RMBA muestran la combinación entre antiguos, nuevos y renovados formatos comerciales.

En este marco, los datos provistos por Google Maps constituyen un insumo importante para la toma de decisiones. La cartografía de centros tradicionales según estándares de equipamiento o presencia de actividad bancaria, contrapuesta al patrón de localización de shopping centers, resulta de gran utilidad, aunque no traduce la continuidad de la actividad comercial y de servicios de los corredores de alcance supramunicipal, característicos de la RMBA, la cual sí es posible verificar con la construcción de mapas de grano más fino, como los elaborados en este trabajo.

La detección de formas y patrones de localización del comercio minorista que superan el par dicotómico "shopping-centro histórico" da cuenta de la potencialidad de estos análisis como insumo para la definición de políticas de planeamiento, actualmente enfocadas casi exclusivamente en intervenciones de CCCA. Más allá de estas iniciativas u otras propuestas limitadas al embellecimiento de la "imagen urbana" (peatonalizaciones, mejora del espacio público, regulación de cartelería, soterramiento de la red eléctrica) y regulación de las alturas de edificación en los centros tradicionales, las características funcionales y tipológicas recurrentes de las centralidades relevadas, reclaman una consideración y tratamiento específicos por parte de los instrumentos de planeamiento y ordenación territorial.

\footnotetext{
18 Se conoce por mantero a la persona que se dedica a la venta callejera, generalmente sin permiso municipal. Las saladitas, por su parte, son complejos feriales (de menor tamaño que la Feria La Salada, ubicada en el partido de Lomas de Zamora) que basan su funcionamiento en la comercialización de productos de marcas apócrifas. ${ }^{19}$ Ciudad de Buenos Aires, La Plata, Lomas de Zamora, San Martín y La Matanza son las localidades con mayor cantidad de comercio informal.
}

ACE, 16 (46) CC BY-ND 3.0 ES | UPC Barcelona, España | Estructura y transformación del comercio minorista en el 17 norte de la región metropolitana de Buenos Aires. DOI: http://dx.doi.org/10.5821/ace.16.46.9889 
Las políticas sobre el comercio minorista incluidas en los planes estratégicos o de desarrollo urbano municipales, en consonancia con las políticas de transporte, espacio público y vivienda, deberían a su vez articularse con los programas provinciales o nacionales de mayor envergadura (rutas, transporte ferroviario, Metrobús, redes de servicios, vivienda social), superando los limites político administrativos que, como hemos visto, tienen poca relevancia en la estructuración del comercio en la RMBA.

\section{Agradecimientos}

Este trabajo fue realizado en el marco del Proyecto de Investigación Científico y Tecnológico (PICT) 2018-01361 "Centralidad, movilidad cotidiana y políticas públicas en el corredor noroeste de la RMBA", desarrollado en el Instituto de Geografía (Facultad de Filosofía y Letras, Universidad de Buenos Aires) y financiado por la Agencia Nacional de Promoción Científica y Tecnológica.

\section{Autoría}

La primera autora realizó la revisión de la literatura y elaboró el marco teórico. La segunda autora construyó la base de datos y elaboró la cartografía. Ambas analizaron los resultados del relevamiento, coescribieron dicha interpretación y elaboraron las conclusiones.

Conflicto de intereses: Las autoras declaran que no hay conflicto de intereses.

\section{Bibliografía}

Abba, A. (2005). Nuevas lógicas de centralidad urbana en el siglo XXI. Área Metropolitana de Buenos Aires. Centro de Investigaciones, Hábitat y Municipio (ClHaM), Documento de trabajo. Ciudad de Buenos Aires: FADU-UBA.

Barata-Salgueiro, T. (2011). The resilience of urban retail areas. En T. Barata Salgueiro \& H. Cachinho (Eds.), Retail planning for the resilient city: Consumption and urban regeneration (pp. 19-44). Lisbon: CEG.

Benach, N. (2000). Nuevos espacios de consumo y construcción de imagen de la ciudad en Barcelona. Estudios Geográficos, 61(238), 189-205. DOI: https://doi.org/10.3989/egeogr.2000.i238.526

Caprón, G. (1996). La ville privée: les shopping centers á Buenos Aires. Tesis Doctoral. Université de Toulouse II le Mirail, Francia.

Carpio-Pinedo, J. (2014). Localización y evolución del comercio y servicios a pie de calle en los entornos urbanos. Factores locales frente a la multi-accesibilidad. El caso de la ciudad de Madrid,
Territorios
en Formación,
6 ,
63-84.
Recuperado
de

http://polired.upm.es/index.php/territoriosenformacion/article/view/2867

Ciccolella, P. (1999). Globalización y dualización en la Región Metropolitana de Buenos Aires. Grandes inversiones y reestructuración socioterritorial en los años noventa. Eure, 25(76), 5-27. DOI: http://dx.doi.org/10.4067/S0250-71611999007600001

ACE, 16 (46) CC BY-ND 3.0 ES | UPC Barcelona, España | Estructura y transformación del comercio minorista en el norte de la región metropolitana de Buenos Aires. DOI: http://dx.doi.org/10.5821/ace.16.46.9889 
Ciccolella, P. (2000). Distribución global y territorio. Modernización y concentración comercial en Argentina en los años noventa. Economía Sociedad y Territorio, // (7), 459-496. DOI: https://doi.org/10.22136/est002000439

Ciccolella, P., Vecslir, L. y Baer, L. (2015). Revitalización de subcentros metropolitanos. Buenos Aires entre la ciudad dispersa y la ciudad compacta. Contexto, 11, 11-28. Recuperado de https://contexto.uanl.mx/index.php/contexto/article/view/85

Comisión Nacional Área Metropolitana de Buenos Aires, CONAMBA (1995). El Conurbano Bonaerense. Relevamiento y Análisis. Buenos Aires: Ministerio del Interior.

Colella, V. (2013). Transformaciones, persistencias y resistencias del territorio: la ribera del Municipio de Vicente López. En V Seminario Internacional de Investigación en Urbanismo (p. 496-511). Barcelona, España: DUOT. Recuperado de http://hdl.handle.net/2099/14468

Confederación Argentina de la Mediana Empresa, CAME. 2016. Centros Comerciales Abiertos. 15 años. 100 ciudades. Revista Comerciar, Edición especial.

Dematteis, G. (1998). Suburbanización y periurbanización. Ciudades anglosajonas y ciudades latinas. En F. Monclús (ed.) La ciudad dispersa (pp. 17-33). Barcelona: Centro de Cultura Contemporánea.

De Mattos, C. (2010). Globalización y metamorfosis metropolitana en América Latina. De la ciudad a lo urbano generalizado. Revista de Geografía Norte Grande, 47, 81-104. DOI: http://dx.doi.org/10.4067/S0718-34022010000300005

García-López, M. y Muñiz Olivera, I. (2007) ¿Policentrismo o dispersión? Una aproximación desde la nueva economía urbana. Investigaciones Regionales, 11, 25-43. Recuperado de https://investigacionesregionales.org/es/article/policentrismo-o-dispersion-una-aproximaciondesde-la-nueva-economia-urbana/

Gehl, J. y Svarre, B. (2013). How to study public life. Washington: Island Press.

Gutman, G. (1997). Transformaciones recientes en la distribución de alimentos en la Argentina. Buenos Aires: Secretaría de Agricultura, Ganadería, Pesca y Alimentos (SAGPyA).

Limonta, G. y Paris, M. (2017). OSM come strumento di monitoraggio dei sistema commerciali urbani. GEAM Geoingegneria Ambientale e Mineraria, 151 (2), 103-108. Recuperado de http://hdl.handle.net/11311/1037433

López de Lucio, R. (2006). Espacio público e implantación comercial en la ciudad de Madrid: calles vs grandes superficies. Cuadernos de Investigación Urbanística 23. Madrid: Instituto Juan de Herrera. Recuperado de http://polired.upm.es/index.php/ciur/article/view/237

Rodriguez, L. (2018). Palermo Viejo: Palermo Soho. Los nuevos espacios de consumo como insumo del turismo urbano. En: J. Mansilla y C. Milano (Coord.), Ciudad de Vacaciones. Conflictos urbanos en espacios turísticos, (pp. 289-326). Barcelona: OACU-Pol.len.

Ruiz Lineros, M. y Marmolejo Duarte, C. (2008). Hacia una metodología para la detección de subcentros comerciales: un análisis para Barcelona y su área metropolitana. ACE: Architecture, City and Environment 3(8), 199-218. DOI: http://dx.doi.org/10.5821/ace.v3i8.2464

ACE, 16 (46) CC BY-ND 3.0 ES | UPC Barcelona, España | Estructura y transformación del comercio minorista en el norte de la región metropolitana de Buenos Aires. DOI: http://dx.doi.org/10.5821/ace.16.46.9889 
Salcedo, R. y De Simone, L. (2013). Una crítica estática para un espacio en constante renovación: El caso del mall en Chile. Atenea 507, 117-132. DOI: http://dx.doi.org/10.4067/S0718-04622013000100008

Sevtsuk, A. (2010). Path and Place: A Study of Urban Geometry and Retail Activity in Cambridge and Somerville, MA. PhD Dissertation. Massachusetts Institute of Technology. Department of Urban Studies \& Planning. Recuperado de https://dspace.mit.edu/handle/1721.1/62034

Truffello, R. y Hidalgo, R. (2015). Policentrismo en el Área Metropolitana de Santiago de Chile: reestructuración comercial, movilidad y tipificación de subcentros. Eure 4(122), 49-74. DOI: http://dx.doi.org/10.4067/S0250-71612015000100003

Vecslir, L. (2018). Los bordes del Shopping Center. Interrogantes acerca de la fragmentación urbana en cuatro enclaves comerciales del eje norte de la región metropolitana de Buenos Aires. riURB Revista Iberoamericana de Urbanismo 14. Recuperado de http://hdl.handle.net/2117/130391

Vecslir, L. y Rodríguez, L. (2018). Centros Comerciales a Cielo Abierto como política de renovación de las centralidades tradicionales en el Conurbano Bonaerense. Territorios, 38, 15-40. DOI: https://doi.org/10.12804/revistas.urosario.edu.co/territorios/a.5499

Vecslir, L. y Ciccolella, P. (2011). Relocalización de las actividades terciarias y cambios en la centralidad en la Región Metropolitana de Buenos Aires. Revista de Geografía Norte Grande, 49, 63-78. DOI: https://dx.doi.org/10.4067/S0718-34022011000200005

Vidal-Koppmann, S. (2010). Nuevas centralidades en la región metropolitana de Buenos Aires ¿complementariedad o competencia con los centros tradicionales vecinos? En Perahia R. y Vidal S. (comps.) Cuestiones territoriales de la región metropolitana de Buenos Aires (pp. 93-111). Buenos Aires: Ediciones FADU / Nobuko.

ACE, 16 (46) CC BY-ND 3.0 ES | UPC Barcelona, España | Estructura y transformación del comercio minorista en el norte de la región metropolitana de Buenos Aires. DOI: http://dx.doi.org/10.5821/ace.16.46.9889 